\title{
Posterior Fossa Syndrome Secondary to Ruptured Cerebellar Arteriovenous Malformation: A Case Report
}

\author{
Asiri $\mathrm{A}^{1 *}$ and Alnaami $\mathbf{I}^{1,2}$ \\ ${ }^{1}$ Department of Neurosurgery, Aseer Central hospital, Saudi Arabia \\ ${ }^{2}$ Department of Neurosurgery, King Khalid University, Saudi Arabia
}

Submission: January 11, 2017; Published: March 08, 2017

*Corresponding author: Ahmed Mohammed Asiri, MBBS, Bachelor Degree in Biochemistry, Neurosurgery Resident at Department of Neurosurgery, Aseer Central hospital, Abha -Saudi Arabia, Saudi Arabia, Tel: +966-17-2317095/ +966508428737; Fax: +966-17-2317303; Email: aalmaqta@gmail.com

\begin{abstract}
Posterior Fossa Syndrome (PFS) is well known surgical complication of posterior fossa pathologies, mainly in pediatrics group. We report 10 years old girl who presented with sudden onset of headache, vomiting and decrease in level of consciousness. Upon arrival to emergency department, her GCS was 7/15. Patient was resuscitated and intubated. Initial brain CT revealed IVH with large volume cerebellar hemorrhage on the left lateral hemisphere extending to the vermis and associated hydrocephalus. CT angiography showed large cerebellar AVM. Patient was admitted to PICU and an external ventricular drainage was inserted. Few days later, she underwent cerebral angiography and embolization of AVM with $80 \%$ obliteration rate. After extubation, patient showed symptoms and signs of PFS that lasted six weeks before she returned gradually to her normal status. To our best knowledge, this is the second case with ruptured cerebellar AVM that was followed by FPS. The exact mechanism remains unclear.
\end{abstract}

\section{Introduction}

Cerebellar mutism or posterior fossa syndrome secondary to arteriovenous malformation is extremely rare [1,2]. In the literatures, there are many well known cases of cerebellar mutism or Posterior fossa syndrome (PFS) secondary to posterior fossa tumor resections [3-7], more in pediatrics patients [6]. PFS manifests by diminished speech ability with a progression to mutism, hypotonia, emotional disturbance and ataxia [5]. Tumor that is more localized to midline in the posterior fossa, mainly in the vermis with extension to brainstem is of a significant risk factor [8]. Medulloblastomas, astrocytomas and ependymomas represent the most common types of tumors. The main age in one study was 10.4 years [8-10].

This syndrome is a transient, usually starts from 0 to 6 days post operation and it may continue to up to four months before gradual resolving $[9,10]$. The recovery range and period is widely variable. Ataxi after 1-2 months post surgery is around $100-85 \%$ while hypotonia and third nerve palsy were $50 \%$ and $40 \%$ respectively [5,11-13]. Motor speech deficits 1 year after the surgey were around 68\% [14]. Other reported complications include variable degree of behavioral and cognitive symptoms like depression, antisocial behavior, anxiety, academic difficulties and poor intellectual ability [15-18].

\section{The Case}

10 years old girl presented with sudden onset of headache and vomiting that was followed by decrease in level of consciousness. Upon arrival to emergency department at our hospital, her GCS was 7/15. No significant past medical history. She was resuscitated and intubated. Initial brain CT revealed IVH with large volume cerebellar hemorrhage on the left lateral hemisphere extending to the vermis and associated hydrocephalus (Figure 1). CT angiography showed large cerebellar AVM. Patient was admitted to PICU and an external ventricular drainage was inserted. Few days later, she underwent cerebral angiography and embolization of AVM with $80 \%$ obliteration rate. After extubation, patient showed signs and symptoms of PFS that lasted for six weeks before she returned gradually to her normal status. 


\section{Open Access Journal of Neurology \& Neurosurgery}

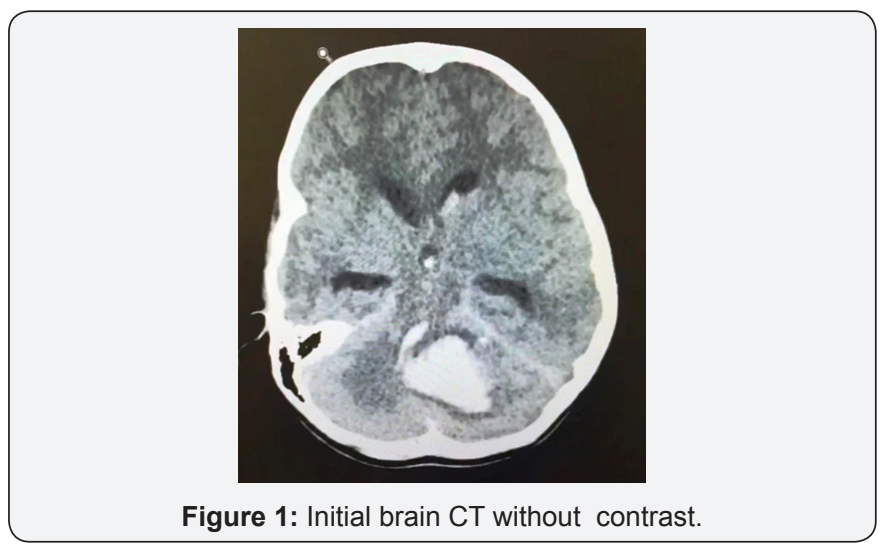

\section{Discussion}

Despite PFS being a challenging syndrome to explain and understand, however, one of the most acceptable explanations to date is dentatorubro-thalamocortical tract being destructed by surgical intervention [4]. In one study using diffusion tensor imaging, a damage to cerebello-thalamo-cerebral pathway at the level of right cerebellar hemisphere in left handed children underwent a medelloblastoma resection was significantly correlated to cerebellar mutism [6].

Posterior fossa syndrom (PFS) in this case followed the regular course of those underwent surgical resection of posterior fossa tumor. Ischemia or infarction due to the primary insult or the intervention might be a possible cause for this phenomenon. In our case, weather endovascular intervention or the lesion itself (AVM) is the cause, the real mechanism remain unknown regardless of suggested hypothesis. It's crucial that (PFS) to be involved in the informed consent for any such pathology involving cerebellum. Treating team, nursing staff and the family should be aware about the possibility of having PFS in their candidate patient for surgical or endovascular intervention involving the posterior fossa. A huge advance has been made in both, the techniques and tools to diagnose and treat neurosurgical patients in the past decade like the introducing of functional MRI. Using tractography technique may help in future to define the definitive cause and mechanism of PFS and to plan surgical intervention that minimizes the risk of developing (PFS). Pharmacological treatment, speech therapy and weather the involvement of the brain stem by the primary insult, surgical or endovascular intervention remain an area for a further research.

\section{Conclusion}

To our best knowledge, this is the third case worldwide with ruptured cerebellar AVM that was followed by FPS. We think it is something to mention to the family and prepare them for such before intervention; however the exact mechanism remains unclear.

\section{References}

1. Al-Anazi A, Hassounah M, Sheikh B, Barayan S (2001) Cerebellar mutism caused by arteriovenous malformation of the vermis. $\mathrm{Br} \mathrm{J}$ Neurosurgery 15(1): 47-50.

2. Baillieux H, Weyns F, Paquier P, De Deyn PP, Mariën P (2007) Posterior fossa syndrome after a vermian stroke: a new case and review of the literature. Pediatr Neurosurg 43(5): 386-395

3. Reed-Berendt R, Phillips B, Picton S, Chumas P, Warren D (2014) Cause and outcome of cerebellar mutism: Evidence from a systematic review. Childs Nerv Syst 30(3): 375-385

4. Pitsika M, Tsitouras V (2013) Cerebellar mutism. J Neurosurg Pediatrics 12(6): 604-614.

5. Law N, Greenberg M, Bouffet E, Taylor MD, Laughlin S, et al. (2012) Clinical and neuroanatomical predictors of cerebellar mutism syndrome. Neuro Oncololgy 14(10): 1294-1303.

6. Robertson PL, Muraszko KM, Holmes EJ, Sposto R, Packer RJ, et al. (2006) Incidence and severity of postoperative cerebellar mutism syndrome in children with medulloblastoma: a prospective study by the Children's Oncology Group. J Neurosurg 105(6 Suppl): 444-451.

7. Van Calenbergh F, Van de Laar A, Plets C, Goffin J, Casaer P (1995) Transient Cerebellar Mutism after Posterior Fossa Surgery in Children. Neurosurgery 37(5): 894-898.

8. Parent E, Scott L (2011) Pediatric posterior fossa syndrome (PFS): nursing strategies in the post-operative period. Can J Neurosci Nurs 33(2): 24-31.

9. Erşahin Y, Mutluer S, Cağli S, Duman Y (1996) Cerebellar Mutism: Report of Seven Cases and Review of the Literature. Neurosurgery 38(1): 60-66.

10. Koh S, Turkel S, Baram TZ (1997) Cerebellar mutism in children: report of six cases and potential mechanisms. Pediatr Neurology 16(3): 218219.

11. Siffert J, Poussaint T, Goumnerova LC, Scott RM, LaValley B, et al. (2000) Neurological dysfunction associated with postoperative cerebellar mutism. J Neurooncology 48: 75-81.

12. Steinbok P, Cochrane D, Perrin R, Price A (2003) Mutism after posterior fossa tumour resection in children: incomplete recovery on long-term follow-up. Pediatr Neurosurg 39(4): 179-183.

13. Grill J, Viguier D, Kieffer V, Bulteau C, Sainte-Rose C, et al. (2004) Critical risk factors for intellectual impairment in children with posterior fossa tumors: the role of cerebellar damage. J Neurosurg 101(2 Suppl): 152158.

14. Gelabert M, Fernandez J (2001) Mutism after posterior fossa surgery. Review of the literature. Clin Neurol Neurosurg 103(2):111-114.

15. Catsman E, Aarsen F (2010) The spectrum of neurobehavioural deficits in the Posterior Fossa Syndrome in children after cerebellar tumour surgery. Cortex 46(7): 933-946.

16. Beckwitt S, Krieger D, O’Neil S, Jubran R, Tavaré CJ (2012) Symptoms before and after posterior fossa surgery in pediatric patients. Pediatr Neurosurg 48(1): 21-25.

17. Wolfe C, Mullins G, Scott JG, McNall-Knapp RY (2007) Persistent psychosocial problems in children who develop posterior fossa syndrome after medulloblastoma resection. Pediatr Blood Cancer 49(5): 723-726.

18. Ronning C, Sundet K, Due-Tønnessen B, Lundar T, Helseth E (2005) Persistent Cognitive Dysfunction Secondary to Cerebellar Injury in Patients Treated for Posterior Fossa Tumors in Childhood. Pediatr Neurosurg 41(1): 15-21. 
This work is licensed under Creative Commons Attribution 4.0 Licens DOI: 10.19080/OAJNN.2017.02.555597

\section{Your next submission with Juniper Publishers} will reach you the below assets

- Quality Editorial service

- Swift Peer Review

- Reprints availability

- E-prints Service

- Manuscript Podcast for convenient understanding

- Global attainment for your research

- Manuscript accessibility in different formats ( Pdf, E-pub, Full Text, Audio)

- Unceasing customer service

Track the below URL for one-step submission https://juniperpublishers.com/online-submission.php 